\title{
Phenotypes and endotypes of severe asthma in children
}

\author{
Young Yoo, MD, PhD \\ Department of Pediatrics, Allergy Immunology Center, Korea University Anam Hospital, Korea University College of Medicine, Seoul, Korea
}

Severe childhood asthma is a complicated and heterogeneous disorder with distinct phenotypes. Children with severe asthma have more persistent symptoms despite receiving treatment, more atopy, greater airway obstruction, and more air trapping than those with mild-to-moderate asthma. They also have higher morbidity and substantial airflow limitations that persist throughout adulthood. Identification of the phenotype clusters and endotypes of severe asthma can allow further modulation of the natural history of severe asthma and may provide the pathophysiologic rationale for appropriate management strategies.

Key words: Severe asthma, Child, Phenotype, Endotype
Corresponding author: Young Yoo, MD, PhD Department of Pediatrics, Korea University Anam Hospital, 73 Inchon-ro, Seongbuk-gu, Seoul 136705 , Korea

Tel: +82-2-920-5090, Fax: +82-2-922-7476,

E-mail: yoolina@korea.ac.kr

Received: 24 August, 2012

Accepted: 28 December, 2012

\section{Introduction}

Children with severe asthma account for about 5\% to 10\% of all patients with asthma ${ }^{11}$. Severe asthma is characterized by persistent chronic symptoms or exacerbations or persistent airflow obstruction despite high-dose inhaled corticosteroid (ICS) therapy with long-acting $\beta$-agonists or leukotriene receptor antagonists ${ }^{2,3)}$. Interest in the heterogeneity of clinical phenotypes and the biological mechanisms underlying severe asthma has substantially increased in recent years. An asthma phenotype includes clinical, physiological, morphologic and biochemical characteristics, as well as the response to different treatments. Although most phenotypes manifest clinically, they do not implicate the underlying disease process. The term asthma endotypes refers to subtypes characterized by a distinct functional or pathophysiological mechanism ${ }^{4}$. This review will discuss recent findings on phenotypes and endotypes of severe asthma in children.

\section{Phenotypes of severe asthma}

\section{Classification of asthma severity}

According to the Global Initiative for Asthma and the National Asthma Education and Prevention Program Guidelines for the Diagnosis and Management of Asthma, asthma can be divided into 4 levels of severity: mild intermittent, mild persistent, moderate persistent, and severe persistent. In children older than 5 years, daytime symptoms, nighttime symptoms, and pulmonary function are key factors in determining the asthma severity. Therefore, severe asthma is defined primarily by the presence of persistent symptoms and lung function abnormalities despite appropriate therapy. There is, however, increasing evidence that this approach does not reflect the heterogeneous characteristics
Copyright @ 2013 by The Korean Pediatric Society

This is an open-access article distributed under the terms of the Creative Commons Attribution NonCommercial License (http://creativecommons.org/ licenses/by-nc/3.0/) which permits unrestricted noncommercial use, distribution, and reproduction in any medium, provided the original work is properly cited. 
Table 1. American Thoracic Society workshop consensus for definition of severe/refractory asthma*

Major criteria (need $\geq 1$ )

Treatment with continuous or near continuous ( $\geq 50 \%$ of year) OCSs

Requirement for treatment with high-dose ICSs

Minor criteria (need $\geq 2$ )

Requirement for additional daily treatment with a controller medication (e.g., LABA, theophylline, or leukotriene antagonist)

Asthma symptoms requiring SABA use on a daily or near-daily basis

Persistent airway obstruction ( $\mathrm{FEV}_{1}<80 \%$ predicted, diumal peak expiratory

flow variability $>20 \%$ )

One or more urgent care visits for asthma per year

Three or more oral steroid bursts per year

Prompt deterioration with a $\leq 25 \%$ reduction in oral or inhaled corticosteroid dose

Near-fatal asthma event in the past

OCS, oral corticosteroid; ICS, inhaled corticosteroid; LABA, long-acting $\beta$ agonist; SABA, short-acting $\beta$-agonist; FEV1, forced expiratory volume in 1 second.

Reprinted from Moore et al. J Allergy Clin Immunol 2007;119:405-13, with permission of Elsevier ${ }^{2)}$

*Requires that other conditions have been excluded, exacerbating factors treated, and patient felt to be generally adherent.

of severe asthma ${ }^{5,6}$. More specific approaches for the differential diagnosis of severe asthma in children are needed to define the heterogeneous phenotypes of this disorder.

\section{SARP definition of severe asthma}

The National Heart, Lung, and Blood Institute (NHLBI) sponsored a workshop titled 'Severe Asthma Research Program' $(\mathrm{SARP})^{7}$. The SARP defined severe asthma in childhood based on the American Thoracic Society (ATS) consensus panel report (Table 1).

\section{Severe asthma clusters}

Severe asthma in children is a heterogeneous disorder with many phenotypes. An SARP cohort defined the phenotypes of 161 children with severe asthma (ATS criteria) on the basis of their clinical features and inflammatory biomarker levels (cluster analysis) $^{8}$. Four clusters of severe childhood asthma were identified: (1) late-onset symptomatic asthma with normal pulmonary function test (PFT) results and less atopy, (2) earlyonset atopic asthma with normal PFT results, (3) early-onset atopic asthma with greater comorbidity and mild airflow limitations, and (4) early-onset atopic asthma with advanced airflow limitations and the greatest symptoms and medication use $^{9 \text { ? }}$.

\section{Characteristics of severe asthma}

\section{Clinical features}

Children with severe asthma have greater airway obstruction, poor symptom control, elevated fractional exhaled nitric oxide (FeNO), and increased allergic sensitization ${ }^{10,11}$. The frequency of asthma exacerbations is higher in children with severe asthma than in those with mild-to-moderate asthma. Children with severe asthma have greater airway obstruction (lower forced expiratory volume in 1 second $\left.\left[\mathrm{FEV}_{1}\right]\right)$ both at baseline and after bronchodilator administration ${ }^{12)}$. Airway hyperresponsiveness to methacholine and lung overexpansion are also greater in children with severe asthma than in those with mild-to-moderate asthma. A marked increase in air trapping is another feature of severe asthma, which is suggestive of a disproportionate involvement of small airways ${ }^{2)}$.

\section{Development of severe asthma}

There are several factors that may lead to the development of severe asthma ${ }^{7,13)}$. (1) Multiple environmental factors and host immune responses are critical for the inception of the disease and the development of a severe form of asthma. Geneenvironment interactions involving certain gene polymorphisms are essential in determining disease expression, progression, and responses to treatment. (2) Allergens are also important factors in the development of asthma; however, it is not clear whether the level of exposure to allergen or the kind of allergens involved are associated with the progression of severe asthma ${ }^{14)}$. (3) Many respiratory viruses, Chlamydia, and Mycoplasma spp have also been shown to be associated with the aggravation of asthma symptoms. Prolonged presence of respiratory pathogens in the lower airway may contribute to both the chronicity and severity of asthma ${ }^{15)}$. (4) Glucocorticoid insensitivity is also likely to play a role in the pathogenesis of severe asthma. Corticosteroid therapy is currently the most potent approach for the treatment of airway inflammation. Thus, failure to respond to corticosteroid therapy is likely to result in persistent airway inflammation, airflow obstruction, and progression to severe asthma. SARP showed that there is a subgroup of children with severe asthma who have extreme morbidity and differentiating clinical features that are identifiable very early in life ${ }^{16}$. Fig. 1 depicts a hypothesis for the development of severe asthma in children ${ }^{16)}$.

\section{Molecular characteristics}

Using the data obtained by Fitzpatrick and colleagues on bronchoalveolar lavage (BAL) and bronchial biopsies, the molecular phenotype of severe asthma in children has become apparent ${ }^{17,18)}$. In BAL fluid, growth-related oncogene (GRO; 


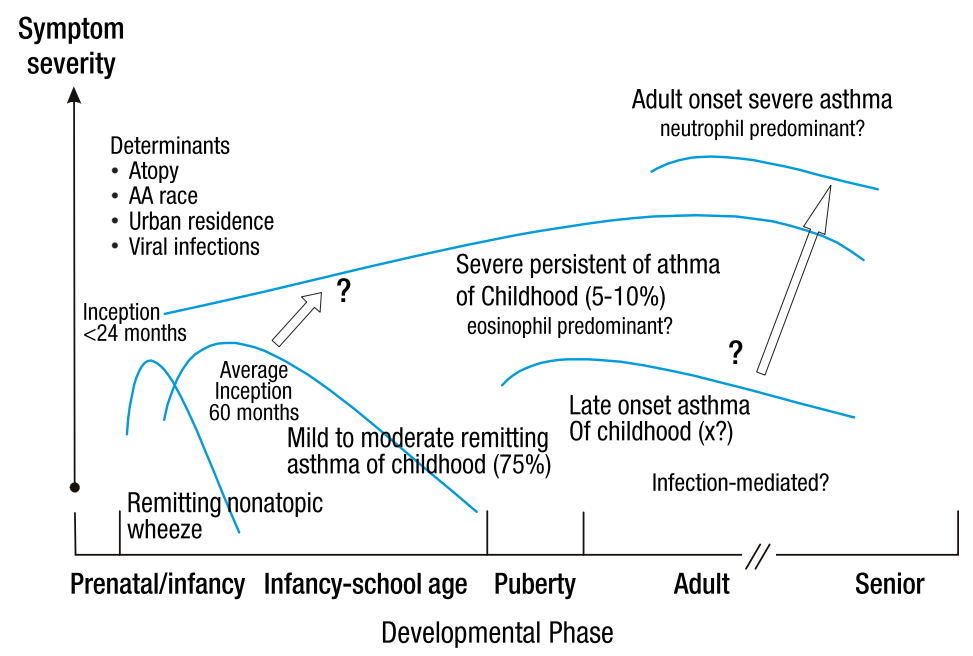

Fig. 1. Hypothesized development of severe asthma in children. Reprinted from Fitzpatrick and Teague. Pediatr Allergy Immunol Pulmonol 2010;23:131-8, with permission of Mary Ann Liebert, Inc. ${ }^{16)}$.

CXCL1), regulated on activation, normal T cell expressed and secreted (RANTES; CCL5), interleukin (IL)-12, and IL-10 can be used to characterize severe asthma in children. Neutrophil chemoattractant GRO (CXCL1), IL-8 (CXCL8), the Th1 cytokine interferon- $\gamma$, as well as the Th2 cytokine IL-13 are also highly expressed in children with severe asthma ${ }^{18)}$. Furthermore, given that the levels of both neutrophils and eosinophils are elevated in children with severe asthma, cellular inflammation appears complex without a clear Th1 or Th2 pattern ${ }^{18)}$. Expression of Th1 and Th17 activate a variety of downstream signaling pathways and induce effects such as glucocorticoid resistance in severe asthma $^{19)}$.

\section{Airway remodeling in severe asthma}

Bronchoscopic studies of patients with severe asthma demonstrate a wide range of cellular inflammatory pattern and structural changes ${ }^{20,21)}$. Histopathologic changes that occur within the airways of severe asthmatics include epithelial desquamation and regeneration, goblet cell hyperplasia, subepithelial fibrosis, or thickening of the basement membrane, inflammatory cell infiltration, hyperplasia and hypertrophy of the bronchial smooth muscle, and vascular changes ${ }^{211}$. Airway remodeling is a distinctive pathologic feature of asthma, which is thought to be the result of an aberrant reparative process associated with ongoing allergic inflammation.

\section{Noninvasive indirect markers of severe asthma}

Indirect and noninvasive methods for the correct diagnosis of severe asthma include induced sputum test, FeNO measurement, exhaled breath condensate analysis, and high resolution computed tomography $(\mathrm{HRCT})^{22)}$. The ATS guidelines sug- gest that FeNO may be useful for detecting eosinophilic airway inflammation and for determining the likelihood of corticosteroid responsiveness. HRCT is a noninvasive technique that may be valuable for assessing airway remodeling in patients with severe asthma ${ }^{23)}$. New noninvasive magnetic resonance-based ventilation scans obtained before and after bronchodilator administration could potentially be more sensitive to the detection of gas trapping and airway narrowing. Position emission tomography-computed tomography imaging studies can be used to spatially map the distribution of active inflammation along the airways and to evaluate the distribution of inhaled therapeutic agents.

\section{Endotypes of asthma}

\section{Moving from phenotypes to endotypes}

Although considerable advances have been made over the past decade in the understanding of severe asthma in children, the next step should be focused on the development of personalized medications for the disorder. However, phenotypic characteristics biologically linked to clinical responses still remain unknown. An endotype is proposed to be a subtype of a condition defined by a distinct pathophysiological mechanism. If the term phenotype describes observable characteristics such as clinical, physiological, and morphological characteristics, the term endotype defines distinct functional and pathophysiological mechanisms for the disease ${ }^{24)}$. 


\section{Endotypes of severe asthma}

Recently, 6 asthma endotypes have been demonstrated, of which at least 4 are relevant to severe asthma ${ }^{25}$. These 4 endotypes are early-onset severe allergic asthma, late-onset persistent eosinophilic asthma, aspirin-exacerbated airway disease, and allergic bronchopulmonary mycoses. Among these, early-onset severe allergic asthma begins in childhood ${ }^{4)}$. Although Th2 inflammation may be a possible mechanism for early-onset severe allergic asthma, this Th2 pathobiology has to be tested for its selectivity for this phenotype. It remains to be determined what percentage of these early-onset patients have severe asthma since childhood. Monoclonal antibodies to immunoglobulin E (IgE)- or Th2-modifying drugs, such as IL-4R receptor antagonist and antibody to IL-13, have been studied in this endotype of severe asthma ${ }^{26)}$.

It is necessary to classify patients according to the underlying mechanisms of their disease rather than their clinical characteristics. Classification of severe asthmatic patients according to endotypes will facilitate future research to establish genetic associations, to identify biomarkers for disease endotypes, and to test novel therapeutic targets and endotypespecific treatments.

\section{Differences between pediatric and adult severe asthma}

SARP confirmed that there is marked heterogeneity in childhood severe asthma similar to that seen in adults with severe asthma ${ }^{27)}$. However, clinical differences in children and adults are considerable. In contrast to adults with severe asthma, children with severe asthma were highly atopic with peripheral blood eosinophilia, aeroallergen sensitivity, elevated serum IgE concentrations, and sustained increases in FeNO concentrations. Children are more likely to be male, to be more sensitive to the suppressive effects of glucocorticoids, and to have less impaired lung function ${ }^{28)}$.

Similar to adults with severe asthma, children with severe asthma are characterized by baseline airflow limitation that is not completely reversed with bronchodilation. However, the magnitude of airflow limitation is significantly less in children with severe asthma as compared to adults. These findings raise important questions regarding the stability of the severe asthma phenotype in children and the critical developmental time frame during which loss of lung function occurs ${ }^{27)}$. Jenkins et al. ${ }^{28)}$ have shown that children with more severe and frequent symptoms have ongoing airflow limitation and more severe asthma throughout adulthood. They also stated that despite higher mean $\mathrm{FEV}_{1}$ values, children with severe asthma displayed a greater annual decline in $\mathrm{FEV}_{1}$ than their adult peers with mild-to-moderate asthma onset in childhood. According to the longitudinal follow-up data from NHLBI's SARP, children with severe asthma have premature loss of lung function during their adolescence, which is associated with an increased frequency of wheezing and asthma symptoms and greater allergic sensitization during childhood ${ }^{299}$.

Interestingly, prepubertal girls with severe asthma have no residual air trapping after maximal bronchodilation, whereas boys with severe asthma have incomplete reversal of air trapping with persistent elevations of $\operatorname{TLC}^{30}$. These findings suggest that the adult physiological patterns of severe asthma are already present in school-age boys but may not yet be fully developed in girls. The years surrounding puberty may be a critical window wherein the phenotype of severe asthma in children is intensified and worsened.

\section{Natural history of severe asthma in childhood}

The risk of asthma persistence increases with severity, allergen sensitization, smoking, and female sex ${ }^{311}$. More severe disease in female subjects may be related to hormonal factors that contribute to the immunological inflammatory processes; some female sex steroids are proinflammatory and increase susceptibility to atopy ${ }^{32)}$.

\section{Conclusions}

Severe childhood asthma is characterized by poor symptom control and persistent airway inflammation despite controller medications including high-dose ICS. Although the revalence of severe asthma is low, children have extremely high morbidity and high health care costs. Severe asthma has the greatest unmet treatment needs to improve asthma control and to reduce exacerbation risk. Certainly, severe childhood asthma becomes more diverse over time and the vast majority of children with severe asthma persist up to adulthood. The use of endotypes in clinical research could identify patient groups that will benefit most from new and existing treatments, substantially improving future asthma care.

\section{Conflict of interest}

No potential conflict of interest relevant to this article was reported. 


\section{References}

1. Antonicelli L, Bucca C, Neri M, De Benedetto F, Sabbatani P, Bonifazi F, et al. Asthma severity and medical resource utilisation. Eur Respir J 2004;23:723-9.

2. Moore WC, Bleecker ER, Curran-Everett D, Erzurum SC, Ameredes BT, Bacharier L, et al. Characterization of the severe asthma phenotype by the National Heart, Lung, and Blood Institute's Severe Asthma Research Program. J Allergy Clin Immunol 2007; 119:405-13.

3. Szefler SJ, Martin RJ, King TS, Boushey HA, Cherniack RM, Chinchilli VM, et al. Significant variability in response to inhaled corticosteroids for persistent asthma. J Allergy Clin Immunol 2002;109:410-8.

4. Lotvall J, Akdis CA, Bacharier LB, Bjermer L, Casale TB, Custovic A, et al. Asthma endotypes: a new approach to classification of disease entities within the asthma syndrome. J Allergy Clin Immunol 2011;127:355-60.

5. Bacharier LB, Strunk RC, Mauger D, White D, Lemanske RF Jr, Sorkness CA. Classifying asthma severity in children: mismatch between symptoms, medication use, and lung function. Am J Respir Crit Care Med 2004;170:426-32.

6. Lang AM, Konradsen J, Carlsen KH, Sachs-Olsen C, Mowinckel $\mathrm{P}$, Hedlin $\mathrm{G}$, et al. Identifying problematic severe asthma in the individual child: does lung function matter? Acta Paediatr 2010;99:404-10.

7. Busse WW, Banks-Schlegel S, Wenzel SE. Pathophysiology of severe asthma. J Allergy Clin Immunol 2000;106:1033-42.

8. Fitzpatrick AM, Teague WG, Meyers DA, Peters SP, Li X, Li H, et al. Heterogeneity of severe asthma in childhood: confirmation by cluster analysis of children in the National Institutes of Health/ National Heart, Lung, and Blood Institute Severe Asthma Research Program. J Allergy Clin Immunol 2011;127:382-9.e1-13.

9. Fitzpatrick AM, Baena-Cagnani CE, Bacharier LB. Severe asthma in childhood: recent advances in phenotyping and pathogenesis. Curr Opin Allergy Clin Immunol 2012;12:193-201.

10. Zeiger RS, Chipps BE, Haselkorn T, Rasouliyan L, Simons FE, Fish JE. Comparison of asthma exacerbations in pediatric and adult patients with severe or difficult-to-treat asthma. J Allergy Clin Immunol 2009;124:1106-8.

11. Gelfand EW. Pediatric asthma: a different disease. Proc Am Thorac Soc 2009;6:278-82.

12. Fitzpatrick AM, Gaston BM, Erzurum SC, Teague WG; National Institutes of Health/National Heart, Lung, and Blood Institute Severe Asthma Research Program. Features of severe asthma in school-age children: atopy and increased exhaled nitric oxide. J Allergy Clin Immunol 2006;118:1218-25.

13. Tillie-Leblond I, Deschildre A, Gosset P, de Blic J. Difficult childhood asthma: management and future. Clin Chest Med 2012; 33:485-503.

14. Sporik R, Holgate ST, Platts-Mills TA, Cogswell JJ. Exposure to house-dust mite allergen (Der p I) and the development of asthma in childhood: a prospective study. N Engl J Med 1990;323:502-7.

15. Kraft M, Cassell GH, Henson JE, Watson H, Williamson J, Marmion BP, et al. Detection of Mycoplasma pneumoniae in the airways of adults with chronic asthma. Am J Respir Crit Care Med 1998;158:9981001.
16. Fitzpatrick AM, Teague WG. Severe asthma in children: insights from the National Heart, Lung, and Blood Institute's Severe Asthma Research Program. Pediatr Allergy Immunol Pulmonol 2010;23:131-8.

17. Brasier AR, Victor S, Ju H, Busse WW, Curran-Everett D, Bleecker E, et al. Predicting intermediate phenotypes in asthma using bronchoalveolar lavage-derived cytokines. Clin Transl Sci 2010;3: 147-57.

18. Fitzpatrick AM, Higgins M, Holguin F, Brown LA, Teague WG; National Institutes of Health/National Heart, Lung, and Blood Institute Severe Asthma Research Program. The molecular phenotype of severe asthma in children. J Allergy Clin Immunol 2010;125:851-7.e18.

19. Poon AH, Eidelman DH, Martin JG, Laprise C, Hamid Q. Pathogenesis of severe asthma. Clin Exp Allergy 2012;42:625-37.

20. Wenzel SE, Szefler SJ, Leung DY, Sloan SI, Rex MD, Martin RJ. Bronchoscopic evaluation of severe asthma; persistent inflammation associated with high dose glucocorticoids. Am J Respir Crit Care Med 1997;156(3 Pt 1):737-43.

21. Jenkins HA, Cool C, Szefler SJ, Covar R, Brugman S, Gelfand EW, et al. Histopathology of severe childhood asthma: a case series. Chest 2003;124:32-41.

22. Bossley CJ, Fleming L, Gupta A, Regamey N, Frith J, Oates T, et al. Pediatric severe asthma is characterized by eosinophilia and remodeling without $\mathrm{T}(\mathrm{H}) 2$ cytokines. J Allergy Clin Immunol 2012;129:974-82.e13.

23. Gupta S, Siddiqui S, Haldar P, Raj JV, Entwisle JJ, Wardlaw AJ, et al. Qualitative analysis of high-resolution CT scans in severe asthma. Chest 2009;136:1521-8..

24. Anderson GP. Endotyping asthma: new insights into key pathogenic mechanisms in a complex, heterogeneous disease. Lancet 2008;372:1107-19.

25. Wenzel S. Severe asthma: from characteristics to phenotypes to endotypes. Clin Exp Allergy 2012;42:650-8.

26. O'Byrne PM, Naji N, Gauvreau GM. Severe asthma: future treatments. Clin Exp Allergy 2012;42:706-11.

27. Jarjour NN, Erzurum SC, Bleecker ER, Calhoun WJ, Castro M, Comhair SA, et al. Severe asthma: lessons learned from the National Heart, Lung, and Blood Institute Severe Asthma Research Program. Am J Respir Crit Care Med 2012;185:356-62.

28. Jenkins HA, Cherniack R, Szefler SJ, Covar R, Gelfand EW, Spahn JD. A comparison of the clinical characteristics of children and adults with severe asthma. Chest 2003;124:1318-24.

29. Fitzpatrick AM, Teague WG; National Institutes of Health/National Heart, Lung, and Blood Institute's Severe Asthma Research Program. Progressive airflow limitation is a feature of children with severe asthma. J Allergy Clin Immunol 2011;127:282-4.

30. Sorkness RL, Teague WG, Penugonda M, Fitzpatrick AM; National Institutes of Health, National Heart, Lung, and Blood Institute's Severe Asthma Research Program. Sex dependence of airflow limitation and air trapping in children with severe asthma. J Allergy Clin Immunol 2011;127:1073-4.

31. Bisgaard H, Bonnelykke K. Long-term studies of the natural history of asthma in childhood. J Allergy Clin Immunol 2010;126:187-97.

32. Lee JH, Haselkorn T, Chipps BE, Miller DP, Wenzel SE; Tenor Study Group. Gender differences in IgE-mediated allergic asthma in the epidemiology and natural history of asthma: Outcomes and Treatment Regimens (TENOR) study. J Asthma 2006;43:179-84. 